\title{
Obstructed defaecation: what is the role of rehabilitation?
}

\author{
F. Pucciani, M. Reggioli and M. N. Ringressi \\ Department of Medical and Surgical Critical Care, University of Florence, Florence, Italy \\ Received 3 November 20 10; accepted 9 February 20I I; Accepted Article online I5 April 20I I
}

\section{Abstract}

Aim The study was designed to evaluate the results of rehabilitative treatment in patients suffering from obstructed defaecation.

Method Between January 2008 and July 2010, 39 patients (37 women, age range 25-73 years; and two men, aged 57 and 67 years) affected by obstructed defaecation were included in the study. After a preliminary clinical evaluation, including the Obstructed Defaecation Syndrome (ODS) score, defaecography and anorectal manometry were performed. All 39 patients underwent rehabilitative treatment according to the 'multimodal rehabilitative programme' for obstructive defaecation. At the end of the programme, all 39 patients were reassessed by clinical evaluation and anorectal manometry. Postrehabilition ODS scores were used to categorize patients arbitrarily into three classes, as follows: class I, good (score $\leq 4$ ); class II, fair (score $>4$ to $\leq 8$ ); and class III, poor ( score $>8$ ).

Results After rehabilitation, there was significant improvement in the overall mean ODS score $(P<0.001)$. Thirty $(76.9 \%)$ patients were included as class I (good results), of whom eight (20.5\%) were symptom free. Five (12.8\%) patients were considered class III. A significant postrehabilitative direct correlation was found between ODS score and pelvic surgery $\left(\rho_{\mathrm{s}}=0.54 ; P<0.05\right)$. Significant differences were found between pre- and postrehabilitative manometric data from the straining test $(P<0.001)$, duration of maximal voluntary contraction $(P<0.001)$ and conscious rectal sensitivity threshold $(P<0.02)$.

Conclusion After rehabilitation, some patients become symptom free and many had an improved ODS score.

Keywords Obstructed defaecation, biofeedback, rehabilitation, multimodal rehabilitation programme, anorectal manometry

\section{What is new in this paper?}

This paper reports results on rehabilitative treatment of obstructed defaecation using the 'multimodal rehabilitative programme', a new structured rehabilitative procedure that is guided by manometric data.

\section{Introduction}

Obstructed defaecation (OD), identified by Bartolo and Roe [1], is broadly defined as the inability to evacuate contents from the rectum [2], with symptoms of dyschezia and a subjective sensation of anal blockage during defaecation. It is a subset of constipation, in that it differs from slow-transit constipation in terms of pathophysiology, due to outlet pelvic obstruction with anorectal dysmotility [3]. Outlet obstruction may be caused by organic or functional diseases, and only diagnostic instruments can identify the causes. Mechanical causes include rectocoele, rectoanal intussusception, descending

Correspondence to: Filippo Pucciani, Department of Medical and Surgical Critical Care, Viale Morgagni 85, 50134 Firenze, Italy.

E-mail: pucciani@unifi.it perineum syndrome, solitary rectal ulcer syndrome, mucosal rectal prolapse, enterocoele and sigmoidocoele. Disorders of rectal sensation and pelvic floor dyssynergia are the functional diseases [3]. In clinical practice, after failure of conservative therapy with high-fibre diet and laxatives, rehabilitation is the first therapeutic option for obstructed defaecation $[2,4]$. Although there are many studies on rehabilitative treatment as first-line therapy in obstructed defaecation caused by pelvic floor dyssynergia [5-9], with an overall success rate of approximately $70 \%$, few reports have been published on the rehabilitative treatment of patients with obstructed defaecation due to mechanical causes $[2,3,10]$.

The purpose of this study was to evaluate the results of rehabilitative treatment and to identify negative factors influencing therapeutic success in the rehabilitative treatment of patients with obstructed defaecation, 
independently from the causes and based on a prospectively constructed database.

\section{Method}

Between January 2008 and July 2010, 156 patients affected by obstructed defaecation with negative coloscopy visited the outpatient unit of the Surgery Clinic of the University of Florence. All were entered into a prospectively constructed database, which contained 1682 patients at the time of the study. Of the 156 patients, $62(39.7 \%)$ failed to respond to conservative medical treatment and were referred for rehabilitative therapy. Exclusion criteria for rehabilitation were age older than 75 years, impaired general health status, neurological disease, physical handicap, general problems (language, distance from the outpatient unit or noncollaboration). Case histories excluded 23 patients from the rehabilitative treatment, as follows: eight patients were over 75 years, three were affected by advanced pulmonary diseases, two had a neurological disease, three a physical handicap and seven had general problems.

The remaining 39 patients [37 women, age range 25-73 years (mean 55.2 years); and two men, aged 57 and 67 years (mean 62.0 years)] were included in the study. All 39 patients received a preliminary clinical evaluation, defaecography and anorectal manometry. They then underwent rehabilitative treatment, performed according to the algorithm of a 'multimodal rehabilitation programme' where all of the rehabilitation procedures were guided by manometric data (Fig. 1). At the end of the rehabilitative programme, all patients were reassessed clinically and by anorectal manometry. In accordance with the ethical guidelines of our university, all of the participants provided written consent to participate in the study with full knowledge of the procedures to be undertaken.

\section{Clinical evaluation}

All patients received a clinical evaluation. Information regarding bowel function according to Rome Criteria III [11] and pathological conditions was noted. We recorded previous pelvic and/or anal surgery, and deliveries in women, noting obstetric tears and episiotomy, and degree of genital relaxation (pelvic organ prolapse quantification) [12]. In all 39 patients, obstructed defaecation was classified according to the Obstructed Defaecation Syndrome (ODS) score [13], which ranged from 0 to 31 . Postrehabilitative ODS scores were arbitrarily assigned to the following three classes: class I, good (score $\leq 4$ ); class II, fair ( score $>4$ to $\leq 8$ ); and class III, poor (score $>8)$.

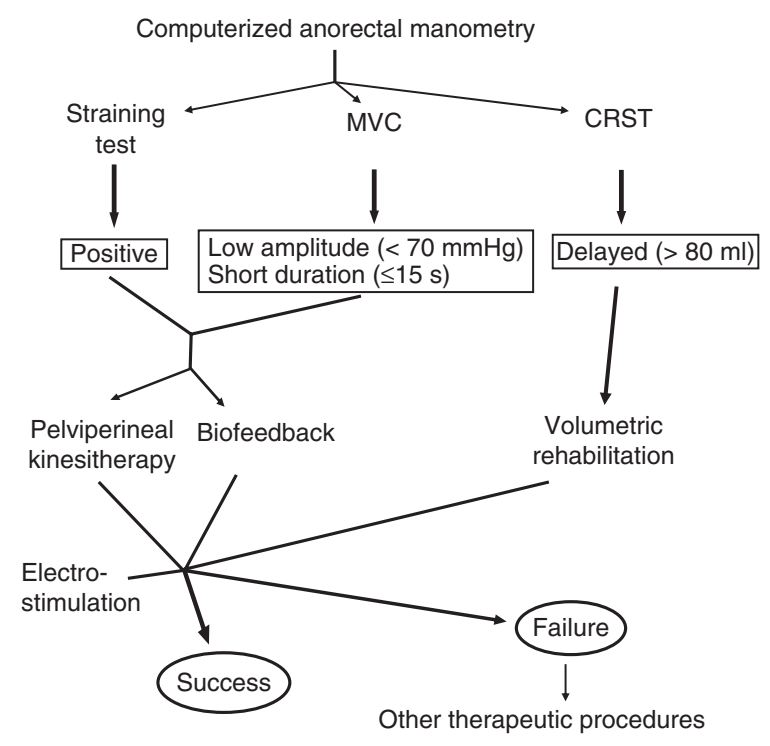

Figure I Algorithm of multimodal rehabilitation programme for obstructed defaecation. A patient with multiple alterations is allocated to multiple techniques in the order of the sequence listed in the text. MVC, maximal voluntary contraction; CRST, conscious rectal sensitivity threshold.

\section{Anorectal manometry}

All patients underwent anorectal manometry. Computerized anorectal manometry was performed in all patients, before and after rehabilitation, using standard techniques [14]. The recordings and the analyses of the traces were made using a computerized system (Dyno Compact; Menfis bioMedica ${ }^{\circledR}$ s.r.l., Bologna, Italy). For anal resting pressure, computerized analysis identified the maximal anal pressure $\left(P_{\max }\right)$ and mean pressure $\left(P_{\mathrm{m}}\right)$. Maximal voluntary contraction (MVC) was evaluated by asking the subject to contract the anal sphincter for as long as possible. The computer quantified the amplitude in millimeters of mercury and duration in seconds. The rectoanal inhibitory reflex (RAIR) was elicited by inflating a soft rubber balloon in the neorectum at $10 \mathrm{~cm}$ from the anal verge: the volume was increased in increments of $20 \mathrm{ml}$ according to Martelli et al. [15]. The first distension volume at which internal sphincter relaxation occurred (RAIR threshold, RAIRT) and the distension volume for which an initial transient sensation occurred (conscious rectal sensitivity threshold, CRST) were recorded in all patients. The maximal tolerated volume (MTV) was also measured in all patients. It was considered to be an expression of rectal reservoir capacity. Compliance of the rectum (expression of the ratio $\mathrm{mmHg} / \mathrm{ml}$ of inflated air) was detected by means of the pressure-volume curve. The manometric procedure ended by measuring anal pressures during attempted defaecation (straining test). This was 
considered positive if an inappropriate rise or a $<20 \%$ relaxation of basal resting pressure occurred. At the end of the rehabilitative programme, all patients were reassessed by anorectal manometry.

\section{Defaecography}

All patients underwent defaecography, according to the method suggested by the Italian working team [16]. It was performed with the patient at rest, during squeeze and during expulsion of the barium. All the X-rays were taken to display latero-lateral views. The radiological measurements included the anorectal angle and the pelvic floor descent. Qualitative evaluation was made by noting rectocoele, rectoanal intussusception and persistence of indentation of the puborectalis during evacuation. The presence of enterocoele, sigmoidocoele or megarectum was noted.

\section{Multimodal rehabilitation}

Multimodal rehabilitation involved pelviperineal kinesitherapy $(\mathrm{PK})$, biofeedback $(\mathrm{BF})$, volumetric rehabilitation (VR) and electrostimulation (ES). Pelviperineal kinesitherapy is a type of muscular training that selectively aims at the levator ani muscles. A cycle of pelviperineal kinesitherapy following a standard sequence of exercises was performed twice weekly in 10 outpatient sessions, according to a previously published scheme [5]. Biofeedback is a conditioning method for the defaecation reflex, which consists of pelvic floor co-ordination exercises together with visual/verbal feedback training. During their first training session, patients received instructions on how to contract and relax the external anal sphincter and puborectalis muscle and how to improve their strength by using modified Kegel exercises. The number of sessions was customized for each patient and was performed at home using portable devices, twice per day for $20 \mathrm{~min}$. The sessions lasted for 1 month [5]. The aim of volumetric rehabilitation was to increase the patient's ability to perceive rectal distension induced by faeces or flatus (rectal sensation). Volumetric rehabilitation involved twice daily administration of a tepid water enema. If the resting conscious threshold was high, the initial volume was equal to the maximally tolerated manometric volume. The patient held the liquid for $1 \mathrm{~min}$. In the following days, the enema volume $(20 \mathrm{ml})$ was gradually decreased until the patient achieved a normal value of rectal sensation. The purpose of anal electrical stimulation was to induce muscle contraction by direct stimulation or indirectly via peripheral nerve stimulation. The rehabilitative cycle was performed daily for 3 months by the patient in a home environment. The device delivered a square wave of current alternating between a 5-6 s work period and a 10-12 s rest period, according to a standard sequence of pulse (width in milliseconds; frequency in herz). All of the rehabilitation procedures were guided by manometric data (Fig. 1). Biofeedback plus PK were indicated by a positive straining test and/or weak MVC. Volumetric rehabilitation (sensory retraining) was indicated for disordered rectal sensation and/or impaired rectal compliance. Electrostimulation was only a preliminary step when the patient needed to improve the sensation of the anoperineal plane. In this way, each rehabilitative technique used was based on the individual patient's manometric reports, resulting in a treatment that was adapted to the patient, given that each rehabilitative technique can modify specific aspects of faecal continence. The usual sequence of procedures was as follows: (I) VR; (II) ES, if necessary; (III) PK; and (IV) BF.

\section{Statistical analysis}

The results are expressed as the means \pm SD. Student's $t$ test for paired and unpaired samples was used for statistical analyses. All correlations were evaluated using Spearman's rank correlation coefficient $\left(\rho_{\mathrm{s}}\right)$. A value of $P>0.05$ was chosen for rejection of the null hypothesis.

\section{Results}

Table 1 shows the clinical characteristics of all 39 patients. Twelve $(30.7 \%)$ had undergone previous

Table I Clinical evaluation.

\begin{tabular}{lc}
\hline & Patients $(39)$ \\
\hline Deliveries* $^{*}$ Obstetric tear* $^{*}$ & $1.1 \pm 0.8$ \\
Episiotomy* & 11 of 37 \\
Pelvic organ prolapse quantification ${ }^{*}$ & 7 of 37 \\
Stage 0 & \\
Stage 1 & 25 of 37 \\
Stage 2 & 9 of 37 \\
Stage 3 & 2 of 37 \\
Stage 4 & 1 of 37 \\
Previous pelvic surgery & 0 of 37 \\
Previous anal surgery & 5 of 39 \\
\hline
\end{tabular}

*Thirty-seven female patients.

$\dagger$ Stage 0, no prolapse; stage 1, leading edge of the prolapse is $>1 \mathrm{~cm}$ above the hymen; stage 2, leading edge of the prolapse is $\leq 1 \mathrm{~cm}$ proximal or distal to the plane of the hymen; stage 3 , leading edge of the prolapse is $>1 \mathrm{~cm}$ below the plane of the hymen but protrudes no more than $2 \mathrm{~cm}$ less the total vaginal length; and stage 4, essentially complete eversion of the total lower genital tract. 
surgery. Four women had had a hysterectomy, and one man had received a transurethral resection. Anal surgery had been performed in seven $(17.9 \%)$ patients, predominantly for haemorrhoids (12.8\%). The degree of genital relaxation, obtained by means of the pelvic organ prolapse quantification examination, is reported in Table 1. Twelve (32.4\%) female patients showed some signs of genital descent. Two (one in stage 2 and one in stage 3 ) had a very high prerehabilitative ODS score (> 24).

The mean prerehabilitative ODS score of the patients was $14.3 \pm 4.2$, with two patients having an ODS score $\geq 24$. Correlations between clinical reports and the prerehabilitative ODS score showed that there was no significant correlation between ODS score and stool frequency $\left(\rho_{\mathrm{s}}=0.13\right)$, pelvic organ prolapse $\left(\rho_{\mathrm{s}}=0.31\right)$ and previous anal surgery $\left(\rho_{\mathrm{s}}=0.11\right)$. A significant correlation was found between the ODS score and previous pelvic surgery $\left(\rho_{\mathrm{s}}=0.64 ; P<0.05\right)$.

Prerehabilitative defaecographic data showed that the pelvic floor descent values in patients were high at rest and during evacuation. Seventeen patients had a poor anorectal angle opening during evacuation, and puborectalis indentation was a defaecographic sign in 14 $(35.8 \%)$ patients; they were considered as affected by pelvic floor dyssynergia according to the coexistence of a manometric positive straining test. Rectoanal intussusception was noted in $13(33.3 \%)$ of all patients, and in eight $(61.5 \%)$ of them the rectoanal intussusception was combined with rectocoele. Rectocoele was present in a total of $23(58.9 \%)$ patients. No signs of enterocoele, sigmoidocoele or megarectum were found.

All 39 patients received a rehabilitation cycle using the multimodal approach. None followed only one rehabilitative technique. Two patients underwent all four rehabilitative procedures; 24 used three techniques (19 patients, $\mathrm{VR}+\mathrm{BF}+\mathrm{PK}$; five patients, $\mathrm{ES}+\mathrm{BF}+\mathrm{PK})$, and 13 patients were treated using only $\mathrm{BF}$ and $\mathrm{PK}$. The mean length of the rehabilitation cycle was $4.1 \pm 1.8$ months. The mean duration of follow up was $11.2 \pm 3.6$ months. The overall mean ODS score showed significant improvement after treatment $(P<0.001$; Table 2). The postrehabilitative ODS score of patients affected by pelvic floor dyssynergia was significantly better $(P<0.038)$ than that of patients with rectoanal intussusception. The patient classification shows that 30 (76.9\%) patients were included as class I and eight were symptom free. Five (12.8\%) patients were included as class III. These patients had a postrehabilitative ODS score that was significantly different from their prerehabilitation score $(P<0.030)$, and four of them had POP stages 3 or 2 associated with rectoanal intussusception. A significant correlation was found between previous pelvic
Table 2 Cumulative Obstructed Defaecation Syndrome (ODS) scores before and after rehabilitation.

\begin{tabular}{lll}
\hline & $\begin{array}{l}\text { Before } \\
\text { rehabilitation }\end{array}$ & $\begin{array}{l}\text { After } \\
\text { rehabilitation }\end{array}$ \\
\hline $\begin{array}{l}\text { Total patients }(n=39) \\
\text { Pelvic floor dyssynergia }\end{array}$ & $14.3 \pm 4.3$ & $2.7 \pm 2.6^{*}$ \\
$(n=14)$ & $13.9 \pm 5.1$ & $1.7 \pm 1.4^{*} \dagger$ \\
$\begin{array}{l}\text { Rectocoele }(n=23) \\
\text { Rectoanal intussusception } \\
(n=13)\end{array}$ & $15.6 \pm 4.5$ & $4.5 \pm 3.6^{*}$ \\
\hline
\end{tabular}

Values are given as means \pm SD.

${ }^{*} P<0.001$, after $v$ s before.

$\dagger P<0.038$, pelvic floor dyssynergia after vs rectoanal intussusception after.

surgery and postrehabilitative ODS score $\left(\rho_{\mathrm{s}}=0.54\right.$; $P<0.05)$.

Table 3 shows the pre- and postrehabilitative distribution of anal resting pressures $\left(P_{\max }\right.$ and $\left.P_{\mathrm{m}}\right)$ and MVC. No significant differences were found between pre- and postrehabilitative basal anal pressure. The recording of MVC shows a mean postrehabilitative MVC duration that reached significant values when compared with that of the prerehabilitative duration $(P<0.001)$. The straining test was considered positive in 14 patients. After rehabilitation, only one patient continued to have inappropriate rise of anal resting pressure during attempted defaecation. The RAIR was detected in all patients. No significant difference was noted between pre- and postrehabilitative RAIRT and MTV data. A significant difference was found between pre- and

Table 3 Rehabilitative manometric data.

\begin{tabular}{lcc}
\hline & $\begin{array}{l}\text { Before } \\
\text { rehabilitation }\end{array}$ & $\begin{array}{l}\text { After } \\
\text { rehabilitation }\end{array}$ \\
\hline$P_{\max }$ & $81.8 \pm 26.9$ & $75.6 \pm 23.1$ \\
$P_{\mathrm{m}}$ & $38.9 \pm 12.1$ & $37.2 \pm 11.7$ \\
MVC-P $(\mathrm{mmHg})$ & $71.2 \pm 39.3$ & $70.1 \pm 34.2$ \\
MVC-T $(\mathrm{s})$ & $19.3 \pm 12.3$ & $31.6 \pm 12.2 *$ \\
RAIRT $(\mathrm{ml})$ & $41.3 \pm 4.7$ & $39.8 \pm 6.7$ \\
MTV $(\mathrm{ml})$ & $184.1 \pm 29.9$ & $181.7 \pm 16.1$ \\
CRST $(\mathrm{ml})$ & $74.8 \pm 37.2 \dagger$ & $58.2 \pm 16.4$ \\
\hline
\end{tabular}

CRST, conscious rectal sensitivity threshold; MTV, maximal tolerated volume; MVC-P, maximal voluntary contraction amplitude; MVC-T, maximal voluntary contraction duration; $P_{\mathrm{m}}$, mean pressure; $P_{\max }$, maximal anal pressure; RAIRT, rectoanal inhibitory reflex threshold.

${ }^{*} P<0.001$, after $v s$ before.

$\dagger P<0.02$, before $v s$ after. 
postrehabilitative CRST ( $P<0.02$; Table 3 ). No modifications of rectal compliance were noted before and after rehabilitation cycles.

\section{Discussion}

Symptoms and signs of outlet obstruction vary from patient to patient and are not correlated with specific anorectal causes. Functional diseases, such as pelvic floor dyssynergia, and organic diseases, such as rectocoele and rectal intussusception, are suspected aetiologies of obstructed defaecation. Our study population confirms the heterogeneity of patients. The defaecographic and manometric data identified the mechanisms of impaired defaecation, pelvic floor dyssynergia $(35.8 \%)$, rectocoele $(58.9 \%)$ and rectoanal intussusception (33.3\%), with descending perineum in the background, as the main causes of altered stool evacuation dynamics. In half (48.7\%) of the patients, there was also a rectal sensation disorder.

The treatment of obstructed defaecation, after failure of medical therapy, is usually oriented towards rehabilitation, but only some patients are capable of doing it. In our survey, $23(37.0 \%)$ patients were excluded from rehabilitative treatment. Once the rehabilitative option has been chosen, however, the problem arises as to how to perform it. There are no international agreements on the use of the various rehabilitative techniques, and the main problems are related to an absence of standards and guidelines. Our multimodal rehabilitation programme is a novelty in the international literature because it is guided by anorectal manometry. It is a useful method for managing the pathophysiology of obstructed defaecation. Each rehabilitative technique can be used when specific damage of a single continence mechanism occurs. In this way, the rehabilitation cycle is tailored to the pathophysiology of obstructed defaecation in the individual patient. All our patients received multimodal rehabilitation using two, three or four rehabilitative techniques. The mean length of the rehabilitation cycle was about 4 months. The overall mean ODS score showed significant improvement after rehabilitative treatment $(P<0.001$; Table 2$)$, and this improvement was obtained independently of the causes; pelvic floor dyssynergia, rectocoele and rectoanal intussusception all had a significantly better postrehabilitative ODS score $(P<0.001$; Table 2$)$, but pelvic floor dyssynergia had better results than rectoanal intussusception $(P<0.038)$. Once all 39 patients were rehabilitated, $30(76.9 \%)$ were categorized as class I with good results, and eight $(20.5 \%)$ of these were symptom free, meaning that some symptom or sign of obstructed defaecation might persist after rehabilitation, but in all probability there will be improvement using rehabilitative treatment. Unfortunately, we did not evaluate the quality of life of our patients and therefore it would be desirable to perform further studies to evaluate the substantial effect of rehabilitative treatment. Only $12.8 \%$ of the patients in our series were included in class III and continued on medical treatment with laxatives and/or enemas. In any case, their postrehabilitative ODS score was significantly different when compared with the prerehabilitation score $(P<0.030)$. These patients had the highest POP stages and rectoanal intussusception, suggesting that the coexistence of both pathologies could be a negative factor for rehabilitation. Postrehabilitative anorectal manometry suggests which mechanisms have been influenced by rehabilitation. Anal relaxation during attempted defaecation, duration of maximal voluntary contraction and rectal sensation (CRST) were significantly modified by rehabilitative techniques. Anal relaxation and endurance of voluntary sphincter contraction are expressions of wellco-ordinated striated muscles, an effect that has been obtained by pelviperineal kinesitherapy and biofeedback. It is important to remember that the co-ordinated sequential activation of muscles, synchronous with motor and sensitive activity of the rectum, is the key to defaecation. Likewise, a normal perception of faecal bolus is determinant to triggering and to maintaining the defaecation, physiological elements that have been restored by volumetric rehabilitation. The irrigations, used in decreasing volumes to modify rectal sensation, achieved their results not as enemas, because the last irrigations were perceived $(40-60 \mathrm{ml})$ as conscious threshold volume but never could trigger defaecation. Therefore, successful rehabilitation of obstructed defaecation must rely on different rehabilitative techniques that achieve different aims. However, it is difficult to identify factors which might influence the rehabilitative results. In our patients, the only positive correlation was between previous pelvic surgery and ODS score $\left(\rho_{\mathrm{s}}=0.54 ; P<0.05\right)$. Previous pelvic surgery could be a cause of iatrogenic damage to pelvic floor muscles, ligaments and pelvic fascia, and rehabilitative techniques might have been unable to influence the postsurgical anatomical arrangement of the pelvis.

In conclusion, rehabilitation of obstructed defaecation provides the opportunity to improve the severity of symptoms in many patients. Moreover, multimodal rehabilitation identifies those 'nonresponders' who should be next in line for more expensive and invasive therapeutic procedures (sacral neuromodulation or surgery). Further studies are mandatory to evaluate the patient's quality of life and long-term results. Last, but not least, because the key to rehabilitative success depends on accurate preselection of patients, the exclusion of negative factors could more precisely identify which patients are more likely to achieve success. 


\section{References}

1 Bartolo D, Roe A. Obstructed defaecation. Br J Hosp Med 1986; 35: 228-36.

2 Khaikin M, Wexner SD. Treatment strategies in obstructed defecation and fecal incontinence. World J Gastroenterol 2006; 28: 3168-73.

3 Andromanakos N, Skandalakis P, Troupis T, Filippou D. Constipation of anorectal outlet obstruction: pathophysiology, evaluation and management. $J$ Gastroenterol Hepatol 2006; $21:$ 638-46.

4 Camilleri M, Bharucha AE. Behavioural and new pharmacological treatments for constipation: getting the balance right. Gut 2010; 59: 1288-96.

5 Pucciani F, Rottoli ML, Bologna A et al. Pelvic floor dyssynergia and bimodal rehabilitation: results of combined pelviperineal kinesitherapy and biofeedback training. Int J Colorectal Dis 1998; 13: 124-30.

6 Chiarioni G, Whitehead WE, Pezza V, Morelli A, Bassotti G. Biofeedback is superior to laxatives for normal transit constipation due to pelvic floor dyssynergia. Gastroenterology 2006; 130: 657-64.

7 Heymen S, Scarlett Y, Jones K, Ringel Y, Drossman D, Whitehead WE. Randomized controlled trial shows biofeedback to be superior to alternative treatments for patients with pelvic floor dyssynergia-type constipation. Dis Colon Rectum 2007; 50: 428-41.

8 Enck P, Van Der Voort IR, Klosterhalfen S. Biofeedback therapy in fecal incontinence and constipation. Neurogastroenterol Motil 2009; 21: 1133-41.
9 Suttor VP, Prott GM, Hansen RD, Kellow JE, Malcolm A. Evidence for pelvic floor dyssynergia in patients with irritable bowel syndrome. Dis Colon Rectum 2010; 53: $156-60$.

10 Lau CW, Haymen S, Alabaz O, Iroatulam AJ, Wexner SD. Prognostic significance of rectocele, intussusception, and abnormal perineal descent in biofeedback treatment for constipated patients with paradoxical puborectalis contraction. Dis Colon Rectum 2000; 43: 478-82.

11 Bharucha AE, Wald A, Enck P, Rao S. Functional anorectal disorders. Gastroenterology 2006; 130: 1510-8.

12 Bump RC, Mattiasson A, Bö K et al. The standardization of terminology of female pelvic floor dysfunction. Am J Obstet Gynecol 1996; 175: 10-7.

13 Altomare DF, Spazzafumo L, Rinaldi M, Dodi G, Ghiselli R, Piloni V. Set-up and statistical validation of a new scoring system for obstructed defaecation syndrome. Colorectal Dis 2008; 10: 84-8.

14 Pucciani F, Rottoli ML, Bologna A et al. Anterior rectocele and anorectal dysfunction. Int J Colorectal Dis 1996; 11: $1-9$.

15 Martelli H, Devroede G, Arhan P, Duguay C, Dornic C, Faverdin C. Some parameters of large bowel motility in normal man. Gastroenterology 1978; 75: 612-8.

16 Piloni V, Genovesi N, Grassi R, Lazzini S, Pieri L, Pomerri F. National working team report on defecography [article in Italian]. Radiol Med 1993; 85: 784-93. 